For equality, we require $X=Y=90^{\circ}$. As expressed by William, this quadrilateral is then 'any shape formed when two right-angled triangles with equal hypotenuse length are placed together, hypotenuse to hypotenuse'.

It is now an easy application of circle geometry to show that equality holds if and only if the original quadrilateral is a cyclic quadrilateral whose diagonals intersect at right-angles.

The first prize of $£ 25$ is awarded to James Moore. The second prize of $£ 20$ is awarded to William Grace.

doi: $10.1017 / \mathrm{mag} .2015 .18$

STAN DOLAN

\title{
Dr John Frankland Rigby
}

(22nd April 1933 - 29th December 2014)

John Rigby, who died in December, was an active member of The Mathematical Association from the day he joined in 1960, serving as President of the Cardiff Branch as well as its meticulous Secretary. He contributed many articles on Euclidean Geometry to the Gazette, which were distinguished by their precision, concise style and freedom from jargon. His elegant solutions to the Problem Corner reflected his encyclopaedic knowledge of results that most of us were not even aware of, and his regular talks at MA Conferences were always a magnet of attraction. He was particularly interested in Japanese traditional geometry with its inherent artistic qualities, as well as the mathematical detail of Islamic and Celtic art. John became a world expert in the connection between mathematics and ornamental art, creating his own designs and patterns which appeared in his beautiful Christmas cards as well as on the hassocks in Cardiff's Llandaff Cathedral.

John was a pupil at The Manchester Grammar School and went on to Trinity College, Cambridge, as both undergraduate and postgraduate. After a stint at GCHQ whilst finishing his $\mathrm{PhD}$, he moved to Cardiff in 1959 to teach in the Mathematics Department of the University and remained there until his retirement. At the same time he became well-known internationally, visiting universities in Turkey, Canada, Singapore, the Philippines and Japan. His former Head of Department, Jeff Griffiths, remembers his wonderful lectures on complex analysis, with inimitable freehand sketches of complicated curves on the blackboard. For many years he ran the University's Mathematics Club for talented sixth-formers in nearby schools, along with his colleague and friend James Wiegold. In this context, Jeff Griffiths writes that

'a worksheet was circulated to the schools a month before each meeting. At the meeting students were invited to present their solution on the blackboard. Although they often produced a technically correct solution, John would inevitably produce a far more elegant one, drawing gasps of admiration from the audience. His perfectly-drawn circles were indeed a wonder to behold'. 
One of his students commented that "Dr Rigby is amazing the way he explains and presents his material and he makes it extremely easy to understand. Why didn't we have him last year?".

In his later years, John suffered from Parkinson's Disease and had an increasingly bad stammer as a result, but that never prevented him from sharing his knowledge of geometry with colleagues at conferences, and, indeed, his diagrams remained as elegant as ever. I can recall his proof of Morley's theorem (and its associated variants) which involved folding tracing paper over a diagram in such a way that the unexpected result seemed to be transparently obvious.

The veteran American author Ross Honsberger gave a special acknowledgment to John in his book Episodes in Nineteenth and Twentieth Century Euclidean Geometry, mentioning his exquisite insightful proofs. In tribute, he named a point in one of John's theorems, concerning the orthopole of the six sides of two triangles, as the Rigby point. It is interesting that he was not the only mathematician to honour John in this way; in a recent article, the two perspectors of the Soddy and tangential triangles were also given that name. John himself was so modest that he would never have claimed these appellations for himself.

In his spare time, he sang in and wrote music for the Cathedral Parish Choir. He was a dedicated defender of wildlife and an ardent supporter of environmental conservation, as well as a keen rambler in the Lake District and along the canals around Manchester. John was also a devoted member of the Welsh Folk Dance Society and a regular participant in both Highland and Scottish country dancing. Indeed, his attraction to patterns led him to devise and publish dances, creating several for the Cardiff Caledonian Society. He will be remembered, by all who knew him, with appreciation, affection and respect, as a remarkable scholar and (in the words of one obituary) a man of culture.

doi: $10.1017 / \mathrm{mag} .2015 .19$

GERRY LEVERSHA

with acknowledgments to Michael Fox, Jeff Griffiths and Isabel Hitchman 